to riclsets. The one feature common to all cases seen by the writer in these countries is some dietary defect, and from this he concludes that rickets is a dietetic disease.

The chief difficulty in accepting a purely dietetic theory for the causation of rickets is the following well-known fact. If a number of children are placed under the same luggienic conditions and fed on a similar ill-balanced artificial diet three things may occur:

(1) The infant may remain quite healthy and develop normally.

(2) Malnutrition may occur without signs of rickets.

(3) Riclrets may appear.

None of the theories so far advanced explains the markedly variable susceptibility to the development of rickets possessed by infants placed under similar conditions of life as regards hygiene and diet. Speaking of infants reared in an institution, Hess $^{3}$ recently said the fact that 25 per cent. of the children fed on the same milk would get rickets and the rest would not, showed that there was some individual idiosyncrasy. If we adopt the dietetic theory of rickets we must go further, and be able to explain why a similar diet given to three infants is capable of producing atrophy in one, rickets in another, while a third child who was similarly treated remained in good health.

Cautley ${ }^{4}$ has endeavoured to explain why the atroplic infant shows no sign of rickets by stating that there is antagonism between the two diseases, the atrophic infant not having " sufficient anabolic vitality for the production of the characteristic proliferative changes in the cartilages and bones." Be that as it may, the fact remains that atrophic infants rarely show signs of rickets. In both these affections, which may be presumed to be due to dietetic causes, as human milk is a specific remedy for one and a prophylactic for the other, there are profound metabolic changes, yet the clinical signs are markedly different. In looking for an explanation which will satisfy all the peculiarities of rickets as shown by labora. tor'y experiments and clinical observation, including the results of therapy, it appears to the writer that one must go further than to assign either a purely dietetic or hygienic etiology for this disease. The profound metabolic changes which occur in a severe case of this disease can, lhe considers, be only caused by. a disturbance of those organs which control metabolism in the young. In the further study of secretions produced by the endocrine organs - "the regulators of metabolism," to quote McCarrison 5-will perhaps be found the key to open the portals which at present hide the mysteries of this disease. If a deficiency of endocrine secretion is the direct result of an unsuitable artificial diet, and the latter is also the chief factor in the causation of rickets, it would perhaps not be illogical to conclude that this disease is the effect of a deficiency of the secretion produced by one or more of these organs. Of the various endocrine organs a deficiency of whose secretion is responsible for the production of rickets I suggest that the thymus gland is the most probable. McCarrison found that in birds and monkeys experimented on with certain diets " the thymus atrophies intensely," but he has no data with regard to the merely scorbutic diet. A plausible reason for considering that rickets is due to thymic insufficiency is that the age incidence of the active growth of the thymus and of the disease known as rickets is almost identical. The normal thymus does not increase in size after the age of 2 years, and rickets as a progressive disease is usually limited to that age. Surely these significant facts are something more than a mere coincidence Then again the peculiar idiosyncrasy to rickets may better be explained by this theory than any other. Still has drawn attention to the wide discrepancy between the weight of the normal thymus gland in infants as noted by different observers, and it is not unreasonable to suggest that Nature has been more lavish in her endow. ment of some infants with a large and active gland than in others. If such should prove to be the case, we can more easily explain those cases (known to all observers) which, in spite of an ill-balanced diet containing (theoretically) insufficient suitable protein or fat and an excessive amount of carbolhydrate, can still remain healthy for a considerable time, because, orving to a highly efficient thymus, a sufficiency of secretion is produced to prevent the onset of this disease. In adranced cases of rickets the spasmophilic manifestations which occur owing to defective hygiene are possibly due to the atroply of other endocrine organs such as the parathyroids. The condition of marasmus or infantile atrophy, which is said to be antagonistic to rickets, may possibly be due to a deficiency of the secretion of other endocrine organs.

The writer has endeavoured to show that rickets is primarily a dietetic disease, being due to either an insufficiency of fresh animal food in an artificial diet, or to defective assimilation (as a result of digestive disturbance) of such food. It remains only to express an opinion as to which of the two great classes of foodstuffs, fat or protein, are responsible for such defective metabolism. As a result of clinical study and a consideration of the experiments of others I have come to the conclusion that a deficiency of suitable protein is the probable cause. The experiments of Paton and Watson would appear to show that in pups rickets is not caused by feeding on slimmed milk, and though I have frequently fed infants on fresh and dried separated milk for several weeks I have never seen rickets occur as a result. The beneficial effects of cod-liver oil in this disease, both as a prophylactic and a curative measure, would at first sight appear to be a stumbling.block to the acceptance of this theory. I know, however, of no evidence that the benefit derived from this form of treatment is due to the fat of the cod-liver oil, alone or in part; and further investigation may show that the extractives contained therein possibly serve as metabolic stimulants or regulators.

\section{Summary of Conclusions.}

1. That rickets is due to a deficiency of fat-soluble A vitamin in the diet has not been proved.

2. It is primarily due to a diet actually deficient in fresh animal food, probably suitable protein, or to a disturbed digestive condition which prevents the assimilation of the same.

3. The striking metabolic changes in rickets are due secondarily to a deficiency of secretion of one or more of the endocrine organs and probably chiefly of the thymus gland.

4. Confinement in young animals, with its attendant evils of lack of sunshine, exercise, and cleanliness, are important factors in increasing the severity of the disease.

1 Cheadle: Artificial Feed REFERENCES

edition, 1905. " Findlay, Freding and Food Disoriters of Infants, sixth A. F.: Ibid., July, 1921, Leopard: Archiv. Ped., March, 1921. \& Hess, edited by Garrod. Batten, and Thursfind: Diseases of Children. Robert: JRiTish MEDICAL JoURNAI. August i4th, 1920. 6 Still G. F.: Diseases of Children, Goodhart and Still, eleventh edition, p. 212..

\section{DIAGNOSIS AND TREATMENT OF PERFORATED DUODENAL ULCER.}

Founded on Forty-one Consecutive Cases. BY

FREDERICK K. SMITH, M.A., M.B., Сн.B., SURGEON, ABERDEEN ROYAL INFIRMARY. AND LECTURER ON CLINICAL SURGERY TO ABIRDEEN ONIVERSITY.

ON looking over the records of my work in the Aberdeen Royal Infirmary during the years 1914-1919 I was struck by the number of cases of perforated duodenal ulcer that came under my care-namely, 12 in 1915, 9 in 1916, 8 in 1917, 9 in 1918, and 3 in 1919, or 41 in all. As this seemed much in excess of previous years, I thouglit it might be of interest to record certain points in the clinical notes of the cases. Owing to the greatly reduced staff in the lospital during that time, the only assistant arailable for me was a senior student who had many duties to perform, hence the notes are not so detailed as I would have liked.

Perforation is the most serious symptom that can occur with duodenal ulcer; it may take place in both acute and chronic ulcer at practically any age. Perforation has been reported in a clild of two months and in a woman aged 77 years, but such cases are exceptional. At the same time the fact must be recognized that duodenal ulcer and its complications is now being found at a much earlier age than was at one time thought to be probable. Perforation is not only the most serious but also the most frequent complication, but the percentage of cases in which it is said to occur varies greatly. Osler, in his Principles and 
Practice of Medicine, stated that perforation occurs in 6. per cent. of all cases. Douglas, in Surgical Diseases of thie Abdomen, says "The frequency of perforation is given as 43 per cent. (Chrostek), 69 per cent. (Collin), and 50 per cent. (Robson)." In the collected papers of the Mayo Clinic (1905-1909) it is stated that in 272 operations for duodenal ulcer perforation was found sixty-six times, and that sixteen of these were acute. The further fact, how ever, must be apparent, that statistics are not accurate, as there are many cases of duodenal ulcer diagnosed either not at all or wrongly. Considering the now acknowledged prevalence of duodenal ulcer any light that can be thrown upon its serious complications must be of value.

\section{Frequency}

The ratio of men to women suffering from duodenal ulcer is rariously given as from 5 or 3 to 1 . In the present series of cases of perforation the ratio was 40 to 1 the one being the only case of perforation in a woman that I have ever seen. From this, and from a study of other hospital statistics in Aberdeen, I get the impression that duodenal ulcer in the female is very rare. Some observers account for the greater frequency of perforation in men by the fact that men are nore liable to trauma, and that the nature and quantity of the food taken is different.

Age.

Most statistics state that duodenal ulcer is commones between the ages of 20 and 60, that is in cases operated upon, but as the majority of the cases had had symptoms for months or years, an earlier age must be taken for the incidence of ulcer. In the preseut series the youngust was a lad of 17 , the next a woman of 19 , the oidest a man of 63 . Of the 41 cases 26 occurred between the ages of 40 and 60,9 between 20 and 40 , and 4 over 60 I. J. Hammond ${ }^{1}$ reports 14 cases of perforation (12 males and 2 females), and states that the greatest number occurred between 20 and 30 .

\section{History of Previous "Indigestion."}

In the majority of cases of perforation there is a history of definite "indigestion" for months or years. In three of the present series there was no previous history of trouble, all stating that they felt perfectly well until the onset of the symptoms. In the bulk of the cases nnder review in which previous symptoms were present, there was a period of exacerbation previous to the perforation arying from a few hours to a week. This seems to be the usual experience, and differs from that of L. J. Hammond, who reported 14 cases to show the absence of clinical symptoms during the stage before perforation. Investigation of the previous history of indigestion usually gives a fairly typical picture of duodenal ulcer-namely, pain and dis comfort coming on two to three hours after a meal, slightly relieved by vomiting and the eructation of gas and com pletcly relieved by the taking of food, also the characteristic night pain; practically all the cases admitted going to bed with mill: and biscuits close at hand.

In the present series the previous history of indigestion varied from tirirty years to several months, though in one case the history was for ono week only.

Dissemination of Fluid after Perforation.

Perforated duodenal ulcers have been divided surgically into three main classes, namely

1. Cases in which the escape of intestinal contents is so profuse as quickly to flood the whole peritoneal cavity.

2. Cases in which the escape is not so profuse but yet constant, and areas of the general peritoneal cavity hecome more gradually filled, usually in a very definite sequence, one part after another.

3. Chronic perforation, in which the leak is so small and gradual that it leads generally to the formation of a localized abscess, owing to the limiting adhesions which have time to occur.

The cases in the present series belong to classes 1 and 2 . In noue of the cases was there any appearance of a localized affection. The second class of case was by far the most common. There was noarly always an interval during which the extravasated contents were limited to a par ticular region of the abdomen. Frequently the couise of the extravasation can be followed clinically by noting the points of most acute tenderness, which seem to correspond to the spreading margin of the fluid. As the fluid leaves the duodenum it tracks along the shelf of mesocolon towards the right kidney pouch, then downivards either on the outer or $^{\prime}$ inner side of the colon to the right iliac fossa, and thereafter flows into the pelvis. When this is full the fluid gradually spreads up the leit side, and finally, in an untreated case, fills the whole peritoneal cavity.

\section{Symptoms of Perforation.}

As regards the symptoms at the onset of perforation, practically all the cases under review told the same story, and when to this was added the previous bistory of indigestion, there was little cloubt as to the nature of the case. The onset is, to my mind, very characteristica very sudden attack of severe, agonizing or excruciating pain in the epigastrium, which tends to "double one up" and gives the feeling of impending death. 'This is quickTy followed, in the majority of cases, by severe prostration or collapse, the degree of which possibly depends upon the amount and rapidity of spread of the escaping flaid. In my cases the onset was variously described as "like an electric shook," "severe burning," "a terrible spasm," "knife-like," "absolute agony," etc. I was struck by the number of patients who spontaneously stated that the pain "doubled them up." The sudden pain is accompanied by respiratory distress, in that the respirations are short, rapid, and difficult, and this, along with the sense of impending death, makes the expression one of great anxiety; the face becomes pale and perspiration stands out in beads on the forehead. The upper part of the abdomen is usually "board-like" on palpation and excessive tenderness is present, especially in the epigastrium.

These symptoms may bo looked upon as the first stage in the condition, and clearly indicate some grave cata. strophe, and, as already stated, when taken with a previous history of "indigestion," should leave no doubt as to the diagnosis. In this stage there is usually some quickening and weakening of the pulse, the temperature is subnormal, and the patient may or may not vomit. In twelve of $\mathrm{my}$ series romiting was noted at the outset, but it may have been a symptom in many more.

This first stage is usually of very short duration, and unfortunately medical men seldom have the opportunity of seeing it as the patient soon passes into what may be termed the second stage, which is characterized more by tenderness and muscular rigidity. In this stage there may be recovery from the colsupse, the pulse and temperature may be normal, there may be little complaint of pain, and the patient may look comparatively well, although in most cases there is still a suggestion of anxiety or restlessness in the expression. Examination of the abdomen reveals very marked rigidity of both recti and usually difficulty in taking a long breath; breathing in the majority of cases is. costal. There is usually also marked tenderness a little to the riglit of the mid-opigastrium, rather below and internal to the tip of the gall bladder-to the right of the middle line above the umbilicus. At this stage there may not be much alteration in the temperature or pulse rate, but as a rale the respirations remain quick; 35 cases in my series had a respiratory rate of from 25 to 30 .

Obliteration or diminution of liver dullness must not be taken as a necessary siga of perforation. Only in two cases was the liver dullness found to be obliterated; in tive it was diminislied.

The time occupied by the first and second stages is usially from one to two hours, and the third stage develops rapidly. The cases come under observation most frequently during this third stage, when diagnosis has bccome more difficult. The fluid has usually found its way to the right iliac fossa and often into the pelvis, and it is now that we find the signs of spreading "peritonitis"; the pulse rate increases and the temperature rises, there may be slight distension of the abdomen, and the tenderness becomes more general; although excessive tenderness may still be made out to the right, of the epigastrium, the tenderness is frequently most marked at this time in the right iliac fossa, and this observation may lead to a diagnosis of acute appendicitis. The phenomenon is accounted for by the fact already mentioned, that the point of greatest tenderness follows the spreading margin of the extravasated fluid. The board-like rigidity has 
probably spread widely from the epigastrium, kut may be still especially marked on the right side. In a few cases vomiting may persist throughout this stage, and when added to the other symptoms may lead to a diagnosis of acute intestinal obstruction. In 7 of the 41 cases it was noted that the bowels had moved freely after the onset of acute symptoms.

As the fluid spreads and the symptoms increase in severity the pulse rate gradually quickens, with or without an accompanying rise in the temperature; but, in fact, the temperature usually now begins to fall. The respirations become more rapid, the abdominal distension becomes more marked, and the patient gradually passes into what may be termed the fourth or moribund stage, characterized by lividity of the face, a rapid thin pulse, and a cold and clammy condition of the skin.

\section{Diagnosis.}

The diagnosis of perforation is easiest in the first and second stages, before there is much distension and before the physical signs reach the right iliac fossa. If, as is usual, a previous history of indigestion resembling gastric or duodenal ulcer is given, then the onset of excruciating pain in the epigastrium, often described as like the ontpouring of boiling fluid, with marked respiratory distress rigidity of the upper part of the riglit rectus muscle, and marked tenderness to the right of the epigastrium, makes the diaguosis of perforation pretty certain.

At later stages various other conditions may be simu. lated, but at all events the symptoms point to an acute abdominal condition requiring early surgical intervention. In two cases in the series the initial incision was made in the appendical region, and on one occasion the diagnosis of renal colic delayed operative interference for twelve hours.

\section{Prognosis.}

All statistics go to prove that the earlier the case is operated upon after perforation the greater the chance of recovery, and there is no doubt that within recent years the mortality has decreased greatly, due partly to the cases being recognized earlier, and partly to improved technique. In the present series of 41 cases there were 5 deatlis, and, for reasons to be seen later, in the cases subse. quent to January, 1916, there were 29 cases with 2 deaths. Taken all over, the time of operation after perforation varied from three hours to three days, the average being a little over seventeen liours, and in 14 cases the tinie was twenty-four or more hours after perforation.

Of the three fatal cases occurring during 1915 the first was that of a male, aged 48, who, twenty-four hours previous to operation, was suddenly struck by a sudden severe pain in the right costal region and also in the right iliac region, spreading rapidly over the whole abdomen. Tor one week previous to this he suffered from discomfort in the upper abdomen. There was otherwise no history of indigestion. Before admission to hospital he was given opium pills. The physical signs were those of an "acute abdomen." At operation a perforation of the first part of the duodenum was found, and in spite of the usual treatment, including drainage, he died in five days with symptoms of acute peritonitis.

The second was a male, aged 36, with symptoms of acute abdomen for eight hours-acute pain, sickness, and vomiting of "coffee grounds." Although the abdomen was full of fluid resembling stomach contents, no perforation could be found, und he died six days later, in spite of epigastric and suprapubic drains. Unfortunately, no post-mortem examination was made drains. Unfortunately, no post-mortem examination was made to confirm the diagnosis, but the history and

The third fatal case during 1915 was that of W. B., aged 52, who was admitted to hospital in a moribund condition, having perforated three days previously, and for whom the only treatment carried out was the insertion of a suprapubic drain under local anaesthesia.

During the years 1916-1919 there were two fatal cases, one in 1916 and one in 1918, out of a total of 29 -that is, 7 per cent. mortality. The first was a lad of 21 years, whose acute sym. ptoms had been present for fully forty-eight hours before admission. He gave a history of sudden pain and collapse, with vomiting of brown material and later showed the presence of bom in the bloo 28 resiration 32 and temperature $100^{\circ}$ at was 128, respirations 32, and temperature $100^{\circ}$. At operation a well marked perforation of the first part of the duodenum was found close to the pylorus. The perforation was sutured, the abdomen washed out, and a suprapubic

The other fatal case was that of W.F., male, admitted twentynine hours after the onset of acute symptoms. Previous to admission he was given first $5 \mathrm{oz}$. of castor oil, followed in about seven bours by 5 grains of calomel and later by several soap and water and turpentine enemata, withont result! on admission be showed the symptoms of an acute abdomen in the final stage and justifiable interference was regarded as being limited to suprapubic drainage under local anoesthesio. died within twelve hours of admission. In this case no post mortem examination was granted and the diagnosis was made from the history and course of the case.

Treatment.

All authorities agree that immediate operation offers the only chance of cure and the best chance of recovery. In the present series all were cases of free perforation, no evidence of localization of any lind being present. The various problems of treatment can be divided into fout distinct sections or steps-namely, (1) the treatment of the perforated ulcer, (2) the treatment of the peritoneal cavity, (3) whether or not drainage should be employed, (4) should gastro-enterostomy be performed?

It is not my intention to discuss all these, but merely to state what steps were talsen in the series of cases quoted.

1. In every case except two the perforation was closed by purse-string suture, frequently reinforced by interrupted cross sutures. In none of the cases was either excision or cauterization performed.

2. The general opinion is that the peritoneal cavity should not be irrigated. My technique is as follows: Having sutured the perforated ulcer, I make a suprapubic opening sufficiently large to allow of the insertion of an a verage sized Keith's drainage tube. I then retract and lift up the edges of the epigastric incision, and gently pour into the abdomen pints of normal saline solution. With my hand inside the abdominal cavity I make sure that the periduodenal regions, especially under the liver, the right renal pouch, and the right colic regions, are well flushed, and siphon off what gathers in the pelvis through the Keith tube. The irrigation is continued until the fluid comes out of the pelvis quite clear. The epigastric incision is then closed, and the suprapubic drain removed without any attempt being made to empty the peritoneal cavity. The suprapubic wound is closed, and the patient subsequently treated in the Fowler position

During 1915, with 12 cases and 3 deaths, the above technique was not the routine one, the process of "mopping" being used in several; but subsequent to January, 1916, irrigation has been used in all the cases. During 1916 and 1917 the suprapubic drain was left in for twenty-four to forty-eight hours, but subsequent to 1917 , being struck by the small amount of fluid which drained away, I closed the suprapubic wound at the time of operation. From 1916 to 1919 inclusive I treated 29 cases, with 27 recoveries, and lnnowing the details of the two fatal cases, I do not think anyone could say that any other method of treatment would have saved them.

As regards the performance of gastro-enterostomy, it is my custom to posipone this until a later date. In the hospital class of patient it frequently appears to be un. necessary, as in only four of the series have I been aslsed for further advice some months after their discharge. Gastro-enterostomy then cured their symptoms.

In a recent textbook on operative surgery one of the steps in the operation for perforated duodenal ulcer is described as fcllows:

"Provide for drainage through the primary incision, through a special opening made in the right loin just below the last rib, and where there is much peritonitis provide pelvic drain.tge through an anterior wound and keep the patient in the Fowler position."

It was this difficulty of drainage that led me to try irrigation, and I was glad to read in Hertzler's The Peritoneum, under treatment of acute general peritonitis, the following:

"There is one condition in which irrigation seems rational. In instances where large amounts of fluid have leell poured into the peritoneal cavity it seems that irrigation may be usefu by removing mechanically foreigu bodies which have escaped from the intestingl lumen. There is no doubt that peritonitis is much enlanced when foreign bodies enter a! ong with tho soch enisanced when foreign bodies enter a! ong with tho be made to remove them before inflammation has been set up be made to remove them before in

To my mind the statistics I have here given warraut a continuance of the irrigation method. 